\title{
A Pure Theory of Aggregate Price Determination
}

\author{
Masayuki Otaki \\ Institute of Social Science, University of Tokyo, Tokyo, Japan \\ E-mail: ohtaki@iss.u-tokyo.ac.jp \\ Received September 6, 2011; revised October 18, 2011; accepted October 26, 2011
}

\begin{abstract}
This article considers aggregate price determination related to the neutrality of money. When the true cost of living can be defined as a function of prices in an overlapping generations (OLG) model, the marginal cost of a firm depends solely on the current and future prices. Thus, the sequence of equilibrium price becomes independent of the quantity of money. Hence, money becomes non-neutral. However, when people hold the extraneous belief that prices increases proportionately with money, this belief becomes self-fulfilling as long as the increment of money and true cost of living are low enough to guarantee full employment.
\end{abstract}

Keywords: Marginal Cost, True Cost of Living, Neutrality of Money, Credibility of Money, Rational Extraneous Belief

\section{Introduction}

As Keynes [1] points out, a disparity exists between macroeconomics and microeconomics on the mechanism of price determination. In microeconomics, prices are governed by marginal costs. However, macroeconomics emphasizes the role of money in the process of aggregate price determination. How are these perspectives related to each other? The present paper explores this disparity between microeconomics and macroeconomics.

The disparity is closely connected to the neutrality of money. Otaki [2,3] has already shown, by using the standard deterministic two-period overlapping generations (OLG) model of production economy, that the equilibrium sequence of the aggregate price can be independent of the quantity of money. However, Lucas [4] proves that the quantity theory of money holds.

These seemingly contradictory results suggest the following theoretical hypothesis: The assumption that prices are determined by marginal costs means that equilibrium production/employment level is an interior solution. That is, the economy is at the imperfect employment.

This interior solution emerges from to the lack of purchasing power of money. By some plausible assumption, the true cost of living becomes a function of the current and future prices independent of quantities. Hence, the nominal reservation wage also depends on these factors. Thus, when the equilibrium current price is equal to the marginal cost, the equilibrium price sequence becomes independent of the quantity of money. If the quantity of money is sufficiently smaller than the equilibrium price level determined beforehand, some individuals are unemployed, and the interior equilibrium emerges without any price stickiness.

In other words, although most new Keynesian economists seem to believe that a price-stickiness assumption or restriction concerning price realignment is unavoidable in obtaining the non-neutrality of money (e.g., Calvo [5], Mankiw and Reis [6], Woodford [7], and Galì [8], money is non-neutral without such frictions in the OLG model.

The boundary solution, namely, the quantity theory of money, can be achieved by the following two conditions. First, people hold the extraneous belief that the price level varies proportionately with the quantity of money. For example, Lucas [4] specifies the equilibrium price function as $p=m \phi(z)$ to support the quantity theory of money under perfect information. This assumption corresponds to the extraneous belief in this article. Second, the increased rate of money, that is, the inflation rate, is sufficiently modest to reduce the true cost of living, and every individual wishes to work.

Under these conditions, for an arbitrarily given money supply, the current price level flexibly adjusts the purchasing power of money to attain the full-employment equilibrium. Thus, one-to-one correspondence is established between the current price level and the quantity of money. Namely, the quantity theory of money holds, and money becomes neutral. 
Consequently, money is intrinsically non-neutral and affects the employment and output level without any price friction, as Keynes [1] tacitly considers. The quantity theory of money is upheld by the extraneous belief that money is only a measure of value and possesses no substantial value.

This paper is organized follows. Section 2 describes the basic model and explains the non-neutrality of money under perfect competition. Section 3 provides the necessary-sufficient condition for supporting the quantity theory of money. It also discusses the difference between the Keynesian and monetarist views on money. Section 4 explains how the methods of injecting money affect the conclusion. Section 5 provides the concluding remarks.

\section{The Basic Model}

\subsection{Optimization Problems of Economic Agents}

\subsubsection{Individuals}

We consider a standard two-period OLG model with money and one perishable good under certainty. Individuals are born with continuum density between $[0,1]$ in each period, and live for two periods: youth and old age. They can supply unit labor at their discretion when they are young. Their disutility is denoted as $\alpha$. The lifetime utility function of each individual $U$ is

$$
U\left(c_{1 t}, c_{2 t+1}, \delta_{t}\right) \equiv u\left(c_{1 t}, c_{2 t+1}\right)-\delta_{t} \cdot \alpha,
$$

where $c_{1 t}$ and $c_{2 t+1}$ are the current and future consumptions of generation $t$ respectively. $\delta_{t}$ is a definition function that takes the value of unity when the individual works and zero when he/she does not work.

$u(\cdot)$ is well-behaved homothetic function that represents the lifetime utility derived from consumption. As Shephard [9] proves, iff the utility function is homothetic, the true unit cost of living becomes a function of prices independent of the consumption quantity.

Although the separability between the consumption stream and leisure seems restrictive, the assumption can be justified by Diewert's [10] discussion.

"Although this (homothetic) assumption is generally not justified when we consider the consumer's overall cost of living index, it can be justified in the context of a subaggregate if we assume that the consumer has a

\footnotetext{
${ }^{1}$ The assumption that each individual can supply only one unit of labor seems to be rather restrictive. However, the distinction between how many individuals a firm employs and how many hours of work it offers to each individual causes, at least theoretically, a difficult dynamic problem, when there is some fixed training costs for employing an individual. Fukao and Otaki [11] have already solved this problem by applying a real business cycle model. Nevertheless, since the purpose of this paper is to show the existence of unemployment due to the shortage of effective demand, we neglect the adjustment of hours worked per individual and normalize the working time as unity.
}

separable subaggregator function, $f(q)$, which is linearly homogenous. In this case, $q$ is no longer interpreted as the entire consumption vector, but refers only to a subaggregate such as 'food' or 'clothing' or some more narrowly defined aggregate."

From the economic perspective, Diewert [10] suggests that aggregation should be performed among similar goods. In this sense, in Equation (1), we assume that consumption and leisure have quite different properties as compared to the current and future consumption. ${ }^{1}$

The budget constraint that each individual faces is

$$
p_{t} c_{1 t}+M_{t} \leq \delta_{t} W_{t}, \quad p_{t+1} c_{2 t+1} \leq M_{t} \text {, }
$$

where $p_{t}$ is the price of the good; $M_{t}$ is the nominal wage; and $M_{t}$ is the nominal money demand of generation $t$ to prepare for future consumption. The profits of the firm can also become the income. However, we assume that all the markets (goods, money, and labor) are in perfect competition. Hence, we can neglect the profits as a source of income.

An individual maximizes Equation (1) on $\left(c_{1 t}, c_{2 t+1}, M_{t}, \delta_{t}\right)$ subject to Equation (2). Since $U$ is homothetic, the true cost of living function $\Psi$, which is the expenditure function to attain a utility level $u$, exists such that

$$
\Psi\left(p_{t}, p_{t+1}, u\right)=f(u) \psi\left(p_{t}, p_{t+1}\right),
$$

where $\psi(\cdot)$ is a linear homogenous function. It also increases with $p_{t}$ and $p_{t+1}$. We can calculate the nominal reservation wage $W_{t}^{R}$ by using the true cost of living function Equation (3) as

$$
W_{t}^{R}=f(\alpha) \psi\left(p_{t}, p_{t+1}\right) .
$$

In addition, the aggregate current consumption function of the young generation $C_{t}$ becomes

$$
C=c\left(\frac{p_{t+1}}{p_{t}}\right)\left[w_{t} l_{t}\right],
$$

where $l_{t}$ is the employment level located within the interval $(0,1)$.

\subsubsection{Firms}

Next, we proceed to the optimization problem of a representative firm. The only production factor is labor. For simplicity, the representative firm faces the constant return production function

$$
y_{t}^{s}=l_{t},
$$

where $y_{t}^{s}$ denotes the output level. Since the firm acts as a price taker, the profits become zero in the equilibrium. Hence, using Equation (4), we obtain the following important difference equation: 


$$
\begin{aligned}
& p_{t}^{*}=W_{t}^{R} \Rightarrow p_{t}^{*}=f(\alpha) \psi\left(p_{t}^{*}, p_{t+1}^{*}\right) \\
& \Leftrightarrow 1=f(\alpha) \psi\left(1, \frac{p_{t+1}^{*}}{p_{t}^{*}}\right) .
\end{aligned}
$$

Thus, we obtain

Lemma 1. If equilibrium employment is located within $(0,1)$, that is, the equilibrium price is determined by the marginal cost, the equilibrium price sequence, $\left\{p_{t+j}^{*}\right\}_{j \geq 0}$, can be determined independently of the sequence of the quantity of money $\left\{M_{t+j}\right\}_{j \geq 0}$. Furthermore, the equilibrium inflation rate, $\rho^{K} \equiv \frac{p_{t+j+1}^{*}}{p_{t+j}^{*}}$, is constant over time.

In addition, to avoid the multiplicity of equilibrium in the goods market, we define the credibility of money as follows.

Definition 1. We say that money is credible when the rational expectation concerning the future value of money $\left\{\frac{1}{p_{t+j}^{*}}\right\}_{j \geq 0}$ is not perturbed by the change of the sequence of nominal money supply $\left\{M_{t+j}\right\}_{j \geq 0}$. This can be represented as follows:

$$
\frac{d p_{t+j}^{*}}{d M_{t+k}}=0, \quad \forall j, k, t \geq 0 .
$$

Credibility of money implies that all individuals believe in the intrinsic value of money (the inverse of the future price level), which is not affected by the quantity of money. In other words, young individuals are ready to accept all forms of additional money at the prevailing price of the good. As long as money is credible, the initial price $p_{t}$ is historically determined by the rational expectation of the previous young generation. Thus, the price $p_{t}$ is endogenously fixed. In other words, the price become sticky not because of frictions concerning the revision of price (menu cost, Calvo rule, etc.) but because of the belief in the stability of the value of money.

\subsubsection{The government}

Finally, we must specify the money supply rule. New money $M_{t}-M_{t-1}$ is injected through the government expenditure $G_{t}$. Thereafter, money is supplied to keep

\footnotetext{
${ }^{2}$ Farmer [12, 13] also exhibits the price stickiness without frictions. He assumes that money socially facilitates the exchange. Owing to the expansion of opportunities for the exchange, increase in the nominal money supply initially stimulates the output, leaving the price intact. However, thereafter, the congestion in markets raises the price gradually and reduces the consumption. Ultimately, money is neutral in the stationary state even in his models.
}

the real cash balance $\left\{\frac{M_{t+j}}{p_{t+j}^{*}}\right\}_{j \geq 0}$ equal to the initial level $m \equiv \frac{M_{t}}{p_{t}^{*}}$. Therefore, using Lemma 1, the real government expenditure $g_{t+j}$ is expressed by

$$
g_{t+j} \equiv \frac{G_{t+j}}{p_{t+j}^{*}}= \begin{cases}M_{t}-\frac{M_{t-1}}{p_{t}^{*}}, & \text { if } j=0, \\ \left(1-\frac{1}{\rho^{K}}\right) m, & \text { if } j \geq 1 .\end{cases}
$$

Note that either $M_{t}$ or $G_{t}$ is the only exogenous variable in our model. In addition, for simplicity, all the goods that the government purchases are assumed to be wasted.

\subsection{Market Equilibrium}

There are three kinds of markets in the model: goods market, labor market, and money market. Following Walras' Law, we confine our attention to the first two markets. When the labor market is in interior equilibrium, $0<l_{t}<1$, the equilibrium nominal wage is equal to the nominal reservation wage $W_{t}^{R}$.

To clarify the discussion, let us define the neutrality of money.

Definition 2. Money is called neutral iff the nominal money supply $M_{t+j}$ never affects the equilibrium real GDP $y_{t+j}^{*}$. Note that $\left\{M_{t+j}\right\}_{j \geq 0}$ contains all the possible paths that are not confined to Equation (8).

From Lemma 1 and Definition 1, it is clear that iff the goods market is located at an interior equilibrium, money is not neutral. Thus, have

Theorem 1. Money is non-neutral iff the goods market is in any interior equilibrium.

Proof. The aggregate demand for the good $y_{t}^{d}$ is defined by

$$
y_{t}^{d}=c\left(\rho^{K}\right) y_{t}^{s}+g_{t+} \frac{M_{t-1}}{p_{t} *} .
$$

The third term of Equation (9) is the aggregate expenditure of the old generation. Substituting Equations (5), (6), (8), and the zero-profit condition of the firm into Equation (9) and using Lemma 1, we obtain

$$
y_{t}^{d}=c\left(\rho^{K}\right) y_{t}^{s}+m \text {. }
$$

Since $y^{*}=y^{d}=y^{s}$, the equilibrium condition of the goods market is

$$
y^{*}=c\left(\rho^{K}\right) y^{*}+m \text {. }
$$

Consequently, if money is credible and $m$ is suffi- 
ciently small, an interior equilibrium exists in the sense that some individuals are unemployed and

$$
0<y^{*}<1
$$

holds. It is evident from (10) that money is non-neutral in any interior equilibrium.

Conversely, if the economy is located at the boundary equilibrium $y^{*}=1$, where prices cease to be equal to marginal costs, by definition, money becomes neutral. Hence, whenever money is non-neutral, the economy is in some interior equilibrium.

When the prices are determined by the marginal cost, the Hicks-Samuelson $45^{\circ}$ line analysis is justified under perfect competition and rational expectations without any exogenous price stickiness. If the expansionary monetary-fiscal policy is implemented, the employment and output increase. Thus, money is non-neutral. The fiscal multiplier is $\frac{1}{1-c\left(\rho^{K}\right)}$, as shown by Kahn [14] and Keynes [1].

Note that the induced effective demand theory, which is summarized by Equation (10), corresponds to the long-run stationary equilibrium without any price friction. This correspondence implies that the friction or stickiness concerning prices is not a necessary condition for the non-neutrality of money. Furthermore, the properties of the basic model clearly differ from the new Keynesian economics, in that money is non-neutral even in the long run and the theory extended in Keynes [1] can be interpreted as the economics of the stationary state.

\section{Sustaining the Quantity Theory of Money}

The previous section proves that money is intrinsically non-neutral, and an expansionary fiscal-monetary policy stimulates employment and output. This section deals with the necessary/sufficient condition for sustaining the quantity theory of money in the basic model.

\subsection{Two Different Briefs on the Value of Money}

The basic model supports the Keynesian view that imperfect unemployment equilibrium emerges from the lack of effective demand without any price friction. Equation (7) and the concept of credibility play crucial roles in this assertion.

Nevertheless, even if money is credible, the value of money is determined by its own future (rational) expectation. Equation (7) also implies that if individuals expect money to become more valuable in the future independent of nominal money supply, it is soon transmitted to its current value appreciation (deflation) and vice versa. Such fragility of the base of the credibility of money is rooted in the fact that money does not provide any utility by itself. These properties of money resemble those of the fiat money we actually use. To sum up, when prices are determined by marginal costs, the value of money is determined not by its quantity but by its credibility. This is considered to be the Keynesian view on money.

In other words, the fact that the price of a good is insensitive or sticky to a monetary shock does not indicate the significant existence of various frictions on the revision of price but the high credibility of money.

However, the monetarist view regards money only as a measure of value; hence, individuals believe that an increase in the quantity of money brings about a proportional price increase and has no effect on the employment and output level under rational expectations.

In comparison with the Keynesian view, which considers that people believe in the intrinsic value of money, the monetarist view entirely lacks the of credibility of money aspect. Friedman and Schwartz [15] consider that money can be circulated solely on the basis of the confidence of others' will.

Although the two concepts of credibility of money and confidence of others' will, appear to resemble each other, the situation where the confidence of others' will becomes indispensable to sustain the monetary economy, by itself, reveals that the credibility of money is entirely lost and that the role of money has become quite restricttive. This is because estimating the will of numerous and anonymous others is far more difficult than assuming that each individual simply believes in the intrinsic value of money. Furthermore, even if the confidence exists, another problem persists.

That is, how much money do young individuals require in exchange for a unit of goods when the credibility collapses? Thus, once the credibility of money is lost, money ceases to have absolute substance and is reduced to the relative measure of value. In such cases, it is plausible for each individual to expect that prices are determined by the quantity of money.

Such a phenomenon occurs in the following two polar cases. In the first case, the economy is located at the fullemployment equilibrium. Here, any additional money does not produce any output. Accordingly, prices increase proportionately with money. Keynes [1] calls this inflation as true inflation.

The second is the polar case of hyperinflation, in which money completely loses credibility and is used only as a measure of value.

Note that the seminal empirical work of Cagan [16], concerning the quantity theory of money, confines the data to the period of hyperinflation in six European countries immediately after World Wars I and II. (Greece is an exception. The data used for Greece belong to the 
World War II period). According to Cagan [16],

"Even a substantial fall in real income, which generally has not occurred in hyperinflations, would be small compared with the typical rise in prices. Relations between monetary factors can be studied, therefore, in what almost amounts to isolation from the real sector of the economy."

However, credibility of money was highly damaged soon after the World Wars. There are two persuasive reasons for this. First, the potential production capacity of the economy was at its lowest. In addition, governments were forced to monetize huge amounts of debt issued for military expenditure. Such aspects of hyperinflation are similar to those of true inflation.

The second reason, which is more important than the first, concerns the incentive of labor supply. When individuals hold the extraneous belief that prices increase proportionately with the quantity of money, the rate of increase of nominal money supply is equal to the equilibrium inflation rate. Once the inflation rate is higher than some threshold, the equilibrium nominal reservation wages begin to exceed the price of the current good.

This is because the true cost of living index $\psi$ becomes extremely high owing to the acceleration of inflation. Consequently, individuals begin to lose their incentive to work. The credibility of money is entirely lost in this polar case. Contrary to Cagan [16], hyperinflation can be regarded as the pathology of the monetary economy.

On the basis of the above discussion, in the next subsection, we shall show how the basic model is transformed into a model that justifies the quantity theory of money.

\subsection{Rational Extraneous Belief and the Monetary Policy}

To transform the basic model into a monetarist model, we need to assume the following.

Assumption 1. Every individual believes that money is not credible and holds an extraneous belief that the price of a good is proportional to the quantity of money. That is, each individual considers that the equilibrium price function takes the following form:

$$
p_{t+j}=\kappa^{-1} M_{t+j}, \quad \forall M_{t+j}, j,
$$

where $\kappa$ is some positive constant.

Under Assumption 1, we can prove the following theorem:

Theorem 2. A rational extraneous belief equilibrium exists under full employment. That is, there exist $p^{f^{*}}$, $\kappa^{f^{*}}$, and $\mu^{f^{*}} \equiv \frac{M_{t+j+1}}{M_{t+j}}$ that satisfy Equation (11) and $y^{*}=1$ for an arbitrarily given $M_{t}$.

Proof. To attain the full-employment equilibrium, the price of the good must exceed the equilibrium reservetion wage. From Equation (7), the equilibrium price $p_{t}^{f^{*}}$ should satisfy

$$
\begin{aligned}
& p_{t}^{f^{*}}>W_{t}^{R} \Rightarrow p_{t}^{f^{*}}>f(\alpha) \psi\left(p_{t}^{f^{*}}, p_{t+1}^{f^{*}}\right) \\
& \Leftrightarrow 1>f(\alpha) \psi\left(1, \frac{p_{t+1}^{f^{*}}}{p_{t}^{f^{*}}}\right) .
\end{aligned}
$$

Since each individual agrees with Equation (11), by substituting it into Equation (12), we obtain

$$
1>f(\alpha) \psi\left(1, \mu^{f^{*}}\right) \text {. }
$$

Because $\psi$ is a continuous and increasing function on $\mu$, taking Equation (7) into consideration, $\mu^{f^{*}}$ must satisfy

$$
\rho^{K}>\mu^{f^{*}} \text {. }
$$

By the continuity of $\psi$, it is certain that there exists $\mu^{f^{*}}$ that satisfies (14).

Condition (14) assures full employment. Next, we determine $\left(p^{f^{*}}, \kappa^{f^{*}}\right)$ in order to be consistent with Equation (11). Note that $y^{*}=1$. Then, using Equations (10) and (11), we obtain

$$
1=c\left(\mu^{f^{*}}\right)+\kappa^{f^{*}} \Rightarrow \kappa^{f^{*}}=1-c\left(\mu^{f^{*}}\right) .
$$

By Equations (11) and (15), we finally determine the equilibrium price function as

$$
p_{t+j}^{f^{*}}=\frac{M_{t+j}}{\kappa^{f^{*}}} .
$$

This equation completes the proof.

We now deal with the case of hyperinflation. To avoid the unboundedness of the current equilibrium price, we make the following assumption:

Assumption 2. There are some individuals whose disutility of labor is zero. Their Lebesgue measure is $\varepsilon$, $0<\varepsilon \ll 1$.

Under this assumption, we obtain the following theorem concerning hyperinflation.

Theorem 3. A rational extraneous belief equilibrium exists where the employment and output level is at its lowest $\varepsilon$. That is, there exist $p^{h^{*}}, \kappa^{h^{*}}$, and $\mu^{h^{*}}$ that satisfy Equation (11) and

$$
y^{*}=l^{*}=\varepsilon .
$$

Furthermore, the equilibrium inflation rate $\rho^{h^{*}}$ is the highest in comparison with the economies described by Theorems 1 and 2.

Proof. From (7), the following inequality is the necessary and sufficient condition that the employment and 
output level is at its lowest $\varepsilon$ :

$$
\begin{aligned}
& p_{t}^{h^{*}}<W_{t}^{R} \Leftrightarrow 1<f(\alpha) \psi\left(1, \frac{p_{t+1}}{p_{t}}\right) \\
= & f(\alpha) \psi\left(1, \mu^{h^{*}}\right) \Leftrightarrow \rho^{K}<\rho^{h^{*}} .
\end{aligned}
$$

By the continuity of $\psi$, there exists $\mu^{h^{*}}$ that satisfies Equation (18).

Next, we prove the existence of $\kappa^{h^{*}}$. Using (10),

$$
\varepsilon=c\left(\mu^{h^{*}}\right) \varepsilon+\kappa^{h^{*}} \Rightarrow \kappa^{h^{*}}=\left(1-c\left(\mu^{h^{*}}\right)\right) \varepsilon .
$$

Finally, by Equation (11), we obtain the equilibrium price function as

$$
p_{t+j}^{h^{*}}=\frac{M_{t+j}}{\kappa^{h^{*}}} .
$$

By Equations (14) and (18), the equilibrium inflation rate is shown as

$$
\rho^{f^{*}}<\rho^{K}<\rho^{h^{*}}
$$

This completes the proof.

\section{The Injection Methods of Money}

In the previous section, we assume that money is supplied through the government expenditure and is equally distributed to each individual. However, this differs from the rule in Lucas [4]. Lucas [4] assumes that new money is injected into the economy as interest on the existing money. In this section, we consider how such a difference in money supply rule affects the conclusions in Theorems 1, 2, and $3 .^{3}$

Let us denote the gross rate of interest of money during period $t$ as $x_{t}$. Hence, the money supply rule obeys

$$
M_{t+1}=x_{t+1} M_{t} \text {. }
$$

In addition, we assume that Assumption 1 holds, and all individuals expect the equilibrium price as in Equation (11).

Then, the budget constraint of each employed individual becomes

$$
\begin{aligned}
& p_{t} c_{1 t}+M_{t} \leq W_{t}, \quad p_{t+1} c_{2 t} \leq x_{t+1} M_{t} \\
& \Rightarrow c_{1 t}+\frac{p_{t+1}}{p_{t} x_{t+1}} c_{2 t} \leq w_{t} .
\end{aligned}
$$

From Equation (11),

$$
p_{t}=\kappa^{-1} M_{t}, p_{t+1}=\kappa^{-1} x_{t+1} M_{t} .
$$

Substituting Equation (23) into (22), we obtain

$$
c_{1 t}+c_{2_{t}} \leq w_{t}=y_{t} \text {. }
$$

\footnotetext{
${ }^{3}$ Otani [17] has already proved that if the money-supply rule differs from Lucas [4], money becomes non-neutral in the more general framework than ours. However, it is not his concern how the change of nominal money supply affects the macro economy.
}

While we assume here that the production functions is Equation (6), in this section $l_{t}$ is assumed to be hours worked per individual. Thus, the values of $m_{t-1}$ and $x_{t}, x_{t+1}$ are irrelevant to an individual's consumptionleisure decision, independent of the form of utility function. This implies the neutrality of money. Consequently, we obtain the following theorem.

Theorem 4. When every individual holds the extraneous belief of (11) and money supply obeys rule (21) money is neutral in the sense that $\left\{x_{t+j}\right\}_{j \geq 0}$ and $M_{t-1}$ do not affect $y^{*}$.

Proof. It is enough to show the unique existence of $\kappa^{*}$. Equation (24) can be reinterpreted as the goods market equilibrium condition. Let us denote the optimal consumption decision as $\left(c_{1}^{*}, c_{2}^{*}\right)$. Note that the equilibrium output $y^{*}$ is independent of equilibrium prices $\left(p_{1}^{*}, p_{2}^{*}\right)$, so are these variables. Then, by Equations (11) and (24),

$$
\begin{aligned}
c_{1}^{*}\left(y^{*}\right)+c_{2}^{*}\left(y^{*}\right)=y^{*} & \Rightarrow \frac{M_{t+j}}{p_{t+j}^{*}}=c_{2}^{*}\left(y^{*}\right), \\
& \Rightarrow \kappa^{*}=c_{2}^{*}\left(y^{*}\right) .
\end{aligned}
$$

This completes the proof.

A monetarist may find Theorem 4 to be very effective at the first glance. Theorem 3 implies that the quantity theory of money is upheld even in the normal economy, at least mathematically. The superneutrality of money is also supported. Nevertheless, some unusual phenomenon will be observed in this economy. That is, even if the economy possesses idling resources and the marginal cost is constant additional money only raises the price level. In other words, the credibility of money is entirely lost in the economy.

Equation (11) in Assumption 1 and Equation (21) are crucial factors. The newly issued money subject to (21) refers to a kind of denomination - the change of the unit of money-and hence, it is possible for individuals to lose the credibility of money. As a result, individuals hold an extraneous belief that prices increase proportionately with the quantity of money. Such a method of injecting money-continuous denomination that reduces money from the absolute substance to the relative measure of value-is scarcely adopted. Therefore, the relevance of Theorem 4 is much lower than that of Theorem 1 .

\section{Concluding Remarks}

We have analyzed the mechanism of aggregate price determination, which closely relates to the problem of the neutrality of money. The results obtained are as fol- 
lows.

First, when the economy stays within imperfect employment equilibrium, the price of the good is determined by its marginal cost, independent of the quantity of money. This conversely implies that imperfect employment equilibrium emerges from the lack of effective demand (or money).

The stickiness of the aggregate price, which the new Keynesian economists emphasize, may not indicate the substantial cost of changing the price, but the high credibility of money. We have succeeded in proving the aggregate price stability by introducing the concept of credibility of money by using a model in which prices can change flexibly in accordance with exogenous shocks.

Second, we have also succeeded in transforming the basic Keynesian model into a monetarist model in which the quantity theory of money is upheld and money is insignificant.

The transformation requires two additional conditions to the basic model. One is the extraneous belief on the equilibrium aggregate price level. That is, all individuals believe that the aggregate price level changes proportionately with the quantity of money. The other is the qualification on the rate of increase of money supply.

Under such an extraneous belief, the inflation rate becomes equal to the rate of increase of money supply. Accordingly, if the rate of increase of money supply is sufficiently low, nominal reservation wages will be lower than the current price of the good. Hence, full-employment equilibrium is attained. Since newly issued money cannot bear any output, the extraneous belief becomes selffulfilling. Keynes [1] calls this case true inflation.

The other polar case is hyperinflation. When the rate of increase of money supply (the inflation rate) is high enough, nominal reservation wages exceed the current price of the good. In such a case, massive unemployment occurs and the production level falls to its lowest. Thus, the quantity theory of money holds.

To sum up, the quantity theory of money is valid in the two polar cases where money loses its intrinsic value and only operates as a relative measure of value. Although the money supply rule, that new money is added as interest on the outstanding money, strengthens the monetarist's view, such a rule is rarely adopted in reality.

\section{References}

[1] J. M. Keynes, "The General Theory of Employment, Interest and Money,” Macmillan, London, 1936.
[2] M. Otaki, “The Dynamically Extended Keynesian-Cross and the Welfare-Improving Fiscal Policy," Economics Letters, Vol. 96, No. 1, 2007, pp. 23-27. doi:10.1016/j.econlet.2006.12.005

[3] M. Otaki, "A Welfare Economics Foundation for the FullEmployment Policy,” Economics Letters, Vol. 102, No. 1, 2009, pp. 1-3. doi:10.1016/j.econlet.2008.08.003

[4] R. E. Lucas Jr., "Expectations and the Neutrality of Money,” Journal of Economic Theory, Vol. 4, No. 2, 1972, pp. 103-124.

[5] G. Calvo, "Staggered Prices in a Utility Maximizing Framework," Journal of Monetary Economics, Vol. 12, No. 3, 1983, pp. 383-398. doi:10.1016/0304-3932(83)90060-0

[6] N. G. Mankiw and R. Reis, "Sticky Information vs. Sticky Prices: A Proposal to Replace the New Keynesian Phillips Curve,” Quarterly Journal of Economics, Vol. 100, No. 2, 2002, pp. 529-539. doi:10.2307/1885395

[7] M. Woodford, "Interest and Prices: Foundations of a Theory of Monetary Policy,” Princeton University Press, Princeton, 2003.

[8] J. Galì, "Monetary Policy, Inflation, and the Business Cycle: An Introduction to the New Keynesian Framework," Princeton University Press, Princeton, 2008.

[9] R. W. Shephard, “Cost and Production Functions,” 2nd Edition, Springer-Verlag, Berlin, 1981.

[10] W. E. Diewert, "Cost of Living Indexes and Exact Index Numbers,” Discussion Paper 09-06, Department of Economics, University of British Columbia, Vancouver, 2009.

[11] K. Fukao and M. Otaki, "Accumulation of Human Capital and the Business Cycle,” Journal of Political Economy, Vol. 101, No. 1, 1993, pp. 72-99.

[12] R. E. A. Farmer, “Sticky Prices,” Economic Journal, Vol. 101, No. 409, 1991, pp. 1369-1379. doi:10.2307/2234890

[13] R. E. A. Farmer, "Nominal Price Stickiness as a Rational Expectations Equilibrium," Journal of Economic Dynamics and Control, Vol. 16, No. 2, 1992, pp. 317-337. doi:10.1016/0165-1889(92)90036-E

[14] R. F. Kahn, “The Relation of Home Investment to Unemployment,” Economic Journal, Vol. 41, No. 162, 1931, pp. 173-198. doi:10.2307/2223697

[15] M. Friedman and A. J. Schwartz, “A Monetary History of the United States1867-1960,” Princeton University Press, Princeton, 1963.

[16] P. Cagan, “The Monetary Dynamics of Hyperinflation,” In: M. Friedman, Ed., Studies in the Quantity Theory of Money, University of Chicago Press, Chicago, 1953, pp. 25-117.

[17] K. Otani, "Rational Expectations and Non-Nuetrality of Money," Weltwirschaftliches, Vol. 121, 1985, pp. $207-$ 216. 